\title{
Public Graduate Medical Education Money Should Fund Residencies in Specialties the Nation Needs
}

\author{
Joshua Freeman, MD
}

(Fam Med. 2020;52(8):545-7.)

doi: 10.22454/FamMed.2020.141466

D oes America have enough physicians for its population? Are current physicians trained in the specialties and practicing in the locations that Americans need? The Association of American Medical Colleges (AAMC) believes that there are too few physicians, and advocates increasing the number of residency positions in the United States. ${ }^{1}$ They note the increased number of physicians graduating from US medical schools as a result of the creation of new schools and larger class size among existing schools, and correctly observe that if the number of residency slots is not also increased, we will not actually get more practicing doctors because these students will simply fill residency positions currently filled by international medical graduates (IMGs). However, the AAMC does not take a position on the question of what specialties those new physicians should be in or where they should practice.

In an important 2012 study, researchers at the Robert Graham Center (RGC) of the American Academy of Family Physicians (AAFP) estimated that by 2025 we would need an additional 52,000 primary care physicians, based on three factors: population growth, population aging, and increased insurance coverage (mainly via the Affordable Care Act, [ACA]). ${ }^{2}$ Additional data available in the RGC's extensive Chartbook on Primary Care in the United States clearly demonstrate that current physicians are not appropriately distributed by specialty or geography. ${ }^{3}$ We need more primary care doctors everywhere, but especially in rural areas, where about $20 \%$ of the US population lives ${ }^{4}$ but fewer than $10 \%$ of doctors practice. ${ }^{5}$

Why is it that the specialties chosen by US doctors do not match community needs? While primary care physicians, especially family physicians, provide care for all members of a community and for smaller communities, subspecialists require a larger population to support their practices, and often require specialized equipment. Thus, they generally practice in larger metropolitan areas. On its face, this makes sense; a rational distribution of physicians would have enough family doctors to care for everyone, with the various subspecialists clustered in larger towns and cities, serving a referred population.

In the United States, however, the medical community is about two-thirds subspecialist and one-third primary care, an inversion of the ratio in most other developed countries, and practice location is overwhelmingly in large cities. Why? First, medical students mostly come from upper middle-class families in the suburbs of major metropolitan areas where schools offer more opportunities (because the districts have more money) and so they do better on standardized tests for admission to college and medical school. These students are likely to want to live and practice in a major metropolitan area similar to the one where they grew up.

Second, most medical schools are located in major metropolitan areas, so even students from smaller towns get used to living in the city. In the academic referral centers where 
the students train, most of their mentors are subspecialists. Faculty also may overtly or subtly disparage primary care. Moreover, the percentage of medical school graduates entering primary care is artificially inflated by counting all those entering internal medicine residencies as "primary care," although most $(75 \%$ or more) enter subspecialties with 2-4 years after residency completion. ${ }^{6}$

The most important factor, however, is probably money. Subspecialists earn more than family doctors. This becomes even more important as students look to the future in the context of their educational debt. This income differential is the direct result of policy decisions to reimburse specialty work at higher rates, particularly for procedures. The primary care/subspecialist pay differential is much smaller in most other developed countries (eg, in Denmark, family physicians earn more than other specialists). ${ }^{7}$

Subspecialty procedures are lucrative for hospitals, which creates an incentive for those hospitals, the main sponsors of residency education, to invest in specialty residencies. Thus, students choose to enter specialties where they can make more money, and hospitals create residency positions in fields that financially benefit the hospital. ${ }^{8}$ In America, the health care system is not designed or staffed to produce a healthy population. It is designed to extract resources from the rest of the economy. The resulting collapse of the mental health and public health systems are on full display in the news every day.

In this issue of Family Medicine, Rittenhouse, Ament, and Grumbach demonstrate that "Sponsoring Institution Interests, Not National Needs, Shape Physician Workforce in the United States." That is, given the opportunity to decide in which specialties to create new residency positions, hospitals (the main sponsors of residencies) choose those which benefit the hospital itself rather than those which create the new physicians that the broader community needs. The organizations that we entrust to produce physicians are operating in their own interest rather than those of society. And they do this with resources coming directly from taxpayers. Should we expect them to act differently?

In fact, the US health care system provides many motivations for them to act just this way. For example, in a rational health system one might expect that there are enough beds for the people who need them for any reason, and that hospitals would not unnecessarily duplicate services (eg, hospital A does great orthopedic and pediatric care, hospital B has cardiac and psychiatric excellence). In the United States, however, hospitals compete with one another. But they do not choose to compete in all service areas; they compete most aggressively for lucrative services. Every hospital wants to have cancer, heart, orthopedic, and neonatal intensive care patients (with insurance) because they are well reimbursed. There is little competition for poorly reimbursed services like primary care, psychiatry, or trauma.

One of the administrators interviewed by Dr Rittenhouse et al stated:

Yeah, in family medicine we need more residents, but I'm not going to pay to train residents for [competitors]. I mean, if they're not going to stay [at our institution], in reality, I would just as soon shrink the program by half.

But if the new residents can make more money for the hospital, that is a different story:

And so the value of the orthopedic program is that it's lucrative for the hospital... it's just the derivative benefit of all that hospital surgical care.

But those "competitors" are the rest of the local community, and other communities in the region that do not have training programs and count on academic centers to produce the doctors that they need. To some degree, we have blurred the boundary between teaching and nonteaching hospitals and essentially privatized the production of the physician workforce. So if a hospital does not think it is getting the physician recruitments it wants to get, it opens a training program to address its own needs even if this duplicates programs in the same city. But, short of changing the entire health system, what might motivate these teaching hospitals to change their practices to produce more of the kinds of physicians America needs?

\section{Money}

The great motivator. In this particular situation, it doesn't require more money, because the bulk of residency costs are already paid for by public funds. The largest amount-at least $\$ 15$ billion per year $(2012)^{10}$ — comes from federal dollars through Medicare. Additional money comes from Medicaid, a state/federal collaboration, in most states. While we have seen extensive use of public money to bail out private interests in this century, notably in 
2009 during the financial crisis and in the current COVID-19 pandemic, probably no industry (other than defense) has benefited as much from feeding at the public trough as hospitals. Critically, Medicare GME funds come with virtually no strings attached. There is no requirement that it be spent to produce more primary care physicians, or physicians in other shortage specialties, even though these are the doctors most needed by taxpayers in the city, state, region, and nation.

There should be such a requirement. All that is needed is a policy change. The federal Center for Medicare and Medicaid Services (CMS) and state Medicaid programs should determine the specialties in which we need more doctors, and require training institutions to produce them, with the penalty of otherwise not receiving GME training dollars. Of course, if a hospital wants to have more orthopedics residents or cardiology fellows to help it make money, it would be welcome to fund them on its own, but if it wants public GME money it should be required to produce family physicians, psychiatrists, general surgeons, and other specialists in shortage. Such a CMS policy would have to be very explicit, because previous efforts, while somewhat increasing primary care physicians, increased the production of nonprimary care specialists by twice as much!11 Indeed, as stated in a 2017 paper by Coutinho et al, "There is little relationship between [primary care graduate medical education] trainee growth and state need indicators." 12

Family physicians are far from blameless in all of this. Increasingly we are designing our residencies to produce graduates to work in the same large health systems we have traditionally complained about. The AAMC would probably not support such a proposal, but it has clear conflicts of interest in this area. Its members are academic health centers, teaching hospitals that profit from training more procedural subspecialists, and medical schools that all want students to be able to choose any field they want, since they charge such high tuition in the first place.

Such a policy would not cater to the venal self-interest of academic health centers and other hospitals. But it is the right thing to do for the health of all people.
CORRESPONDENCE: Address correspondence to Dr Joshua Freeman at jfreeman@kumc.edu.

\section{References}

1. Association of American Medical Colleges. AAMC Statement on Introduction of Senate GME Expansion Legislation. https:/www.aamc.org/news-insights/press-releases/https/ wwwprodcmsaamcorg/news-insights/press-releases/aamcstatement-introduction-house-gme. Published February 5, 2019. Accesed March 14, 2019.

2. Petterson SM, Liaw WR, Phillips RL Jr, Rabin DL, Meyers DS, Bazemore AW. Projecting US primary care physician workforce needs: 2010-2025. Ann Fam Med. 2012;10(6):503509.

3. Petterson S, McNellis R, Klink K, Meyers D, Bazemore A. The State of Primary Care in the United States: A Chartbook of Facts and Statistics. Washington, DC: The Robert Graham Center; January 2018. https://www.graham-center. org/content/dam/rgc/documents/publications-reports/reports/ PrimaryCareChartbook.pdf. Accessed August 3, 2020.

4. Statista. Size of the urban and rural population of the United States from 1960 to 2019. New York: Statista [software program] 2020. https://www.statista.com/statistics/985183/ size-urban-rural-population-us/. Accessed August 3, 2020.

5. Cromartie J. Population \& Migration. Washington, DC: US Department of Agriculture, Economic Research Service; May 26, 2012. http://www.ers.usda.gov/topics/rural-economypopulation/population-migration.aspx. Accessed August 3, 2020.

6. Petterson S, Burke M, Phillips R, Teevan B. Accounting for graduate medical education production of primary care physicians and general surgeons: timing of measurement matters. Acad Med. 2011;86(5):605-608.

7. PracticeLink. Physician Compensation Worldwide. https:// journal.practicelink.com/vital-stats/physician-compensationworldwide/. Published Fall 2009. Accessed August 3, 2020.

8. Weida NA, Phillips RL Jr, Bazemore AW. Does graduate medical education also follow green? Arch Intern Med. 2010;170(4):389-390.

9. Rittenhouse DR, Ament AS, Grumbach K. Sponsoring institution interests, not national plans, shape physician workforce in the United States. [published online ahead of print July 16, 2020]. Fam Med. https://doi.org/10.22454/ FamMed.2020.507727.

10. Congressional Research Service. Federal Support for Graduate Medical Education: An Overview. https://fas.org/sgp/crs/ misc/R44376.pdf. Washington, DC: Congressional Research Service; updated December 27, 2018. Accessed August 3, 2020.

11. Chen C, Xierali I, Piwnica-Worms K, Phillips R. The redistribution of graduate medical education positions in 2005 failed to boost primary care or rural training. Health Aff (Millwood). 2013;32(1):102-110.

12. Coutinho AJ, Klink K, Wingrove P, Petterson S, Phillips RL Jr, Bazemore A. Changes in primary care graduate medical education are not correlated with indicators of need: are states missing an opportunity to strengthen their primary care workforce? Acad Med. 2017;92(9):1280-1286. 